\title{
Memória dos jesuítas portugueses e história da educação brasileira
}

\author{
Maria Juraci Maia Cavalcante \\ Universidade Federal do Ceará
}

\section{Resumo}

Trata da relação entre a memória histórica dos Jesuítas portugueses radicados no Brasil, por meio da Missão Setentrional dos Jesuítas Dispersos, e a construção da História da educação brasileira, através de uma aproximação de sentido e vínculo temporal entre a obra de Serafim Leite, História dos Jesuítas no Brasil (1933-1950) e a de Fernando de Azevedo, A Cultura Brasileira (1943). Reconhece a proximidade temporal e a afinidade ideológica entre a obra dos dois autores, pela ênfase dada por ambos ao papel educativo dos jesuítas no processo de colonização do Brasil e posição crítica dirigida à política pombalina de expulsão.

Palavras-chave: Memória. Jesuítas. Historia da Educação 


\section{The memory of the Portuguese jesuits and the history of brazilian education}

This paper studies the relationship between the historical memory of the Portuguese Jesuits settled in Brazil, through the Northern Mission of the Dispersed Jesuits, and the construction of the history of Brazilian education, using an approximation of tenor and temporal relationship between the works of Serafim Leite, "History of the Jesuits in Brazil" (1933-1950) and Fernando de Azevedo, "Brazilian Culture" (1943). This paper recognizes the temporal link and ideological affinity between the work of the two authors, due to the emphasis given by both the educational role of the Jesuits in the process of colonization of Brazil and their critical position as to Pombal's policy of expulsion.

Keywords: Memory. Jesuits. History of Education.

\section{Memoria de los jesuitas portugueses y la historia de la educación brasileña}

Se trata de la relación entre la memoria histórica de los jesuitas portugueses que se establecieron en Brasil, dentro de la Misión Jesuita Norte dispersa; la historia de la construcción de la educación brasileña, con una aproximación de sentido; y la relación temporal entre la obra de Serafim Leite, Historia de los Jesuitas en Brasil (1933-1950) y Fernando de Azevedo, Cultura brasileña (1943). Reconoce la proximidad temporal y la afinidad ideológica entre la obra de los dos autores, el énfasis dado tanto por la función educativa de los jesuitas en el proceso de colonización de Brasil y la postura crítica dirigida a la política de expulsión dirigida por Pombal.

Palabras-clave: Memoria. Jesuitas. Historia de la Educación. 


\section{Introdução}

A temática por nós delineada neste artigo recebe inspiração da concepção de método desenvolvido por Ricouer (2007), que entende a memória como dimensão fenomenológica, a história como questão epistemológica e o esquecimento como parte da trama dos sujeitos históricos e campo de enquadramento hermenêutico. É nosso intuito esboçar uma perspectiva crítica da história da educação brasileira, que resulta de nossas incursões em dilemas inscritos numa investigação mais abrangente, abordando a volta dos jesuítas portugueses ao Brasil, em especial, ao Ceará, a partir da perseguição sofrida por esta ordem, após o advento da República em Portugal, em 1910, e de sua expulsão, a 2 de fevereiro de 1911, por meio da reedição do decreto do Ministro de D. José, de 1759.

Em função dessa expulsão da Companhia de Jesus, juntamente com todas as outras ordens religiosas de Portugal, é concebida e iniciada, conforme o livro de Azevedo (1986), a Missão Setentrional da Província Portuguesa Dispersa, dirigida à antiga colônia do Brasil, onde a Companhia de Jesus baseara grande parte do seu projeto de cristianização, por dois séculos, até a expulsão por ordem de Pombal.

Devido a sua suposta hegemonia religiosa junto à população em geral, podemos aquilatar o que representou para a Igreja Católica e os jesuítas, em particular, a perseguição a eles dirigida pelos novos representantes políticos de Portugal.

Os Proscritos, libelo escrito por Gonzaga de Azevedo, noticia em dois volumes, publicados - o primeiro em 1910, na Espanha, e o segundo, em 1914, na Bélgica - as circunstâncias da perseguição e expulsão dos religiosos da Companhia de Jesus, após a revolução de 5 de outubro de 1910, em Portugal.

Tais livros tiveram, segundo explicita o próprio autor, padre da Companhia de Jesus, a função de autodefesa pública numa situação de exílio, razão pela qual tais escritos adquiriram grande ressonância social na época. Nas páginas introdutórias do seu livro, ele salienta que esse episódio ficou registrado nos anais da história portuguesa, como a terceira expulsão dos jesuítas de Portugal, antecedida que foi pela de 1759, por Pombal; e a de 1834, pelas forças do monarquismo liberal e constitucionalista. Essa problemática foi estudada, mais recentemente, pelo historiador abaixo, ocupado com a construção do mito dos jesuítas em Portugal:

[...] Primeiro temos o grande momento fundador da sistematização do mito, operada no governo pombalino (1750-1777), e que se deveu ao protagonismo de Sebastião José de Carvalho e Melo; na sequência deste epicentro criador do mito e desta poderosa construção mobilizadora, teremos o grande ponto de chegada final, que se verificou com a instauração da I República (1910).

[...] Não deixaremos de ressalvar, na nossa análise, que esta reedição da eficácia persecutóra do mito voltou a acontecer num período intermédio (1833-1834), embora com menores significado e expressão histórico-cultural, no âmbito do processo de destituição do regime neo-absolutista de D. Miguel e da reinstauração da monarquia representativa de inspiração liberal. (Franco, 2006, p. 30) 
Assim, na condição de proscritos, os intelectuais jesuítas adotam com alarde a posição de vítimas da incoerência republicana em Portugal. Retornam ao Brasil como integrantes de uma importante Missão, que envolveria, tanto o fortalecimento da fé católica em desafiador território republicano, quanto a construção de uma narrativa capaz de evidenciar o papel da Companhia de Jesus na formação cultural do Brasil. Nesse sentido, expressam a sua disposição de luta pelo resgate da memória histórica da Companhia, numa perspectiva justiceira, delineando assim uma operação de combate ao esquecimento causado por seus perseguidores, em três momentos históricos distintos, configurando aquilo que Ricouer (2007) chamaria de memória justa.

\section{0 mito, a memória história dos jesuítas e a historiografia}

Em função de inúmeras circunstâncias de perseguição - especialmente, em Portugal e na França, que ajudam a criar “o mito jesuíta”, conforme Leroy (1999) e Franco (2006) - é sabido que os jesuítas se ocupam de forma obstinada com o registro de suas ações, o que fazem desde a fundação da Companhia, tanto com o objetivo de angariar apoios e simpatias por parte da Igreja e meio católico, quanto para se defender de seus opositores.

Inácio de Loyola, como dirigente máximo, sediado em Roma, instituiu as famosas cartas missionárias, pela função que tinham no âmbito da administração e controle exercido por ele, sobre as missões enviadas ao Oriente, Europa e América, desde o século XVI. As cartas deram origem a uma prática que favoreceu a formação de arquivos e, consequentemente, de informações minuciosas sobre a memória e a história da Congregação Jesuítica.

A preocupação com a formação teológica e a prática dos famosos exercícios espirituais, que aliam razão e fé, favorecem sobremaneira a formação intelectual dos seus integrantes e o gosto de alguns jesuítas pela história da religião, em geral, e da Companhia de Jesus em particular.

No que se refere à construção dessa memória histórica dos jesuítas no Brasil, o estudo do historiador e padre Serafim Leite é um bom exemplo. Nesse sentido, consideramos muito significativa a visão que ele desenvolve da história missionária da Companhia de Jesus, ressaltando, por um lado, o coincidir da sua fundação com a reforma protestante, a expansão das navegações portuguesas; por outro, o desafio imposto aos jesuítas, devido ao contraste de nível cultural, medido em escala evolucionista, entre as populações por eles encontradas no Japão e no Brasil, a qual podemos apreciar em nota preliminar de um dos seus livros:

A Companhia de Jesus nasceu numa Europa agitada por efervescências reformadoras, quando o mundo já se desvendara todo nos seus contornos geográficos, graças aos descobrimentos marítimos iniciados no século XV pelos Portugueses, movimento que 0 
Mediterrâneo cedia o passo ao Atlântico e, com o Atlântico e, a outros oceanos. A Homero e Virgílio, poetas do Mediterrâneo, sucedia Camões, que em vez de Polífemo, encerrado num antro da Sicília, canta o gigante Adamastor, prosopopeia do Cabo das Tormentas, no extremo sul da África, dominado pelos Portugueses e crismado por eles Cabo da Boa Esperança, trânsito do Atlântico para os mares do Oriente. E sucedeu que no mesmo ano de 1549, em que um navio português deixou Manuel da Nóbrega na costa sul atlântica do Novo Mundo (Brasil), outros navios portugueses tinham levado Francisco Xavier a Malaca, donde passou ao Japão. E estes - o Brasil no Ocidente e o Japão no outro extremo do mundo - são os dois marcos entre os quais se situa a acção missionária portuguesa.

[...]

Breve relance missionário, este, donde emerge a chegada de Xavier ao Japão e de Nóbrega ao Brasil, circunstância sincrónica inicial a sugerir uma reflexão ou confronto. 0 Japão era país de alta cultura, o Brasil achava-se ainda na idade da pedra. A experiência mostrou que os métodos tinham de ser diferentes. Como também diversos haviam de ser os resultados. 0 Japão e os outros países do Oriente continuam a ser pagãos com pequenas minorias cristãs. 0 Brasil é a maior nação católica do mundo, verificação que enunciámos há largos anos e passou a ser lugar-comum, sem se tornar por isso menos real e verdadeiro.(Leite,1993, p. 291)

Neste livro, Serafim Leite nos oferece dois apêndices: 1) o primeiro, de caráter topográfico geral, foi retirado de sua obra maior sobre as missões jesuítas no Brasil, contendo a relação de instituições criadas pela Companhia de Jesus, desde a Amazônia ao Rio da Prata e fronteiras de Oeste, entre 1549 e 1760; 2) o segundo é de natureza cronológica e demarca no tempo a presença de missionários jesuítas no Brasil, nomeando-os e assinalando as datas de seus nascimentos e mortes, bem como do período em que lá estiveram.

0 referido autor assinala a criação de um total de 400 aldeias jesuíticas, no período já assinalado, lista os monumentos construídos que sobreviveram ao tempo e relaciona a toponímia atual de localidades. Salienta ainda que:

[...] em quase todas as aldeias de catequese foram criadas vilas, ao deixarem-nas os missionários, recebendo novas denominações tiradas da toponímia portuguesa metropolitana, como: Abrantes, Almada, Arês, Alter do Chão, Aveiro, Barcelos, Beja, Boim, Borba, Bragança, Caxias, Colares, Faro, Melgaço, Mirandela, Monção, MonteAlegre, Oeiras, Outeiro, Pinhel, Pombal, Santarém, Serpa, Soure, Viana, Viçosa, Vila Verde e outras. (Leite, 1993, p. 253)

Quanto à localização dos colégios e seminários, das residências, igrejas e aldeias fundadas pelos missionários jesuítas no Brasil colonial, até a expulsão pombalina, em 1759, prossegue Serafim Leite o seu relato, apresentando uma lista detalhada de instituições, com a intenção de mostrar a dimensão extraordinária da obra missionária dos jesuítas no Brasil, para ressaltar que a Companhia não deixou de existir após a perseguição de Pombal e confirmar o seu prestígio, no momento em que escreve a sua história. Vejamos o trecho abaixo: 
A história que se intentou neste livro, consagrada à actuação construtiva da Companhia de Jesus no Brasil, conclui-se aqui, não sem esclarecer que a instituição não se dissolveu de todo na Europa. Restabelecida oficialmente pela Santa Sé em 1814, voltou ao Brasil em 1841, onde floresce de novo em colégios, universidades, missões, obras sociais e ministérios religiosos, com a perpétua e multiforme afirmação do pensamento católico na renovada variedade dos tempos. Nem a obra do passado se obliterou com a crise do século XVIII. Ainda hoje a Companhia de Jesus no Brasil vive muito do prestígio antigo, sobretudo com os 3 grandes nomes de permanente evocação: Nóbrega, Anchieta e Vieira. (Leite, 1993, p. 233)

Na revista Brotéria, periódico mais importante da Companhia de Jesus em Portugal, encontramos vários artigos do Padre Serafim Leite publicados, que estão relacionados ou não com a sua obra magna sobre a história da Companhia de Jesus no Brasil, à época colonial, disposta em 10 volumes, a qual serviu como fonte para a historiografia da educação brasileira.

Em visita de consulta à Casa dos Escritores em Lisboa, sede daquele periódico, encontramos alguns dos seus volumes com indicações biográficas do Padre Serafim Leite, como é o caso de Maurício (1970) e Pinho (1990). Estes dois autores noticiam que Padre Serafim nasceu em São João da Madeira, no ano de 1880. Migrou com familiares para o Brasil aos 15 anos de idade, com quem trabalhou na região do Pará e teve contato com a cultura indígena. Entrou para a Ordem dos Jesuítas, em 1914, tomando parte, assim, da Missão Setentrional da Província Portuguesa Dispersa.

É considerado um dos principais historiadores da Companhia de Jesus no Brasil. Falecido em 1969, continua a ser festejado e rememorado por seus pares até os dias de hoje. Por essa razão, começamos por explorar o seu percurso biográfico, onde está claro que a ele foi dada a missão específica de historiar os feitos educativos dos jesuítas, no Brasil colonial.

Sobre o percurso formativo de Serafim Leite, até chegar à sua obra maior, encontramos que:

Tras unos ãnos en el seminario menor de Carvalhos, diócesis de Oporto, dejá sus estudios y se embarcó para el Amazonas (Brasil), donde se dedicó al comércio en Pará. Al volver a Europa (1914), hizo un retiro en Alsemberg entró en la CJ. Estudió humanidades (1916 - 1919) en Murcia (Espãna) y filosofía (1919 - 1922) en Granada (Espãna) y teologia (1923 - 1927) en Enghien.

Em 1929 fue adscrito a la plantilla de la revista Brotéria, de Lisboa, donde escribió sobre temas literarios, apologéticos y socio-culturales. En 1933 comenzó a elaborar su monumental História da Cia de Jesus no Brasil, desde sus comienzos hasta la expulsión de la C.J. por Pombal (1760). Al salir los primeros volúmenes (1938), recebió el Prémio Alexandre Herculano; los restantes ocho volúmenes aparecieron entre 1943 y 1950 [...]. (Dicionário Histórico de la Compãnia de Jesús, 2001, p. 23262327) 
Segundo a mesma fonte, entre 1933 e 1962, Serafim Leite publicou mais de duas centenas de artigos retirados da sua obra magna, submetidos a inúmeras reuniões científicas no Brasil, em Portugal e outros lugares. Ele teria sido membro das academias portuguesa e brasileira de letras, do Instituto Histórico de Roma e outras instituições culturais. Ele também recebeu conderações dos governos brasileiro (1960) e português (1938) e o título de Doutor Honorífico da Universidade Católica do Rio de Janeiro (1949).

A circulação do referido historiador jesuíta e sua obra no meio político, religioso e acadêmico no Brasil, principalmente, entre as décadas de 1930 e 1940, com o apoio inclusive do Ministro Gustavo Capanema para a publicação de alguns dos seus livros, nos faz indagar sobre o impacto do seu estudo sobre a obra missionária e educativa dos jesuítas no Brasil colonial para a construção da visão de Fernando de Azevedo sobre a influência das missões jesuíticas na edificação do sentido da educação colonial, conforme o título que deu ao primeiro capítulo do seu famoso ensaio, intitulado A Cultura Brasileira, publicado em primeira edição, na cidade de São Paulo, pelo Instituto Brasileiro de Geografia e Estatística (IBGE), em 1943, e, no ano seguinte (1944), pela Companhia Editora Nacional.

Apesar de ter sido um dos expoentes do movimento da Escola Nova no Brasil e considerar o ensino jesuítico portador de uma pedagogia tradicional, o ardor com que Fernando de Azevedo se refere ao papel da Companhia de Jesus na edificação da cultura brasileira mostra como ele está em consonância com o modo de Serafim Leite de exaltar os jesuítas em sua ação educativa, citando-o inclusive por inúmeras vezes. Ao tomá-lo como referência básica dessa reconstituição histórica, Azevedo mostra-se irmanado com o ideal de lançar loas à Companhia. Rememoremos o primeiro parágrafo do seu famoso livro:

A vinda dos padres jesuítas, em 1549, não só marca o início da história da educação no Brasil, mas inaugura a primeira fase, a mais longa dessa história, e, certamente, a mais importante pelo vulto da obra realizada e sobretudo pelas consequências que dela resultaram para nossa cultura [...]. (Azevedo,1958, p. 09)

Várias outras passagens do seu livro mostram o entusiasmo de Azevedo, sua visão eurocêntrica e vivamente positiva daquela missão. Mesmo dialogando com a posição de Gilberto Freyre, que destaca em Casa Grande \& Senzala (1933) o caráter destruidor de culturas indígenas da ação dos missionários, Azevedo se curva ao efeito civilizador dela:

Não fôssem os jesuítas que se tornaram os grandes guias intelectuais e sociais da Colônia, durante mais de dois séculos e teria sido talvez impossível ao conquistador lusitano resguardar dos perigos que a assaltavam, a unidade de sua cultura e de sua civilização.[...] Seja qual for o ponto de vista de que se considere a obra realizada pelos jesuítas, ela não pode deixar de impressionar, não só pela extensão da área social em 
que se projetou, da Bahia até Olinda e, para o sul, até São Vicente no século XVI, e de Pernambuco ao Pará, no século XVII, mas também pelas dificuldades que tiveram que vencer, para realizá-la e mantê-la numa sociedadae heterogênea, de brancos, negros, índios e mestiços, baseada num regime de escravidão, fraccionada em núcleos dispersos por grandes distâncias e cindida por lutas e dissenções internas [...]. (Azevedo, 1958, p. 18/19)

A descrição do ensino jesuítico e o destaque à rede de colégios da Companhia existente no Brasil colonial é toda apoiada no estudo de Serafim Leite. 0 texto de Azevedo na edição aqui analisada é enriquecido por fotografias de igrejas e colégios jesuíticos em Santos, Salvador, Paranaguá, Recife; destaca que o Seminário de Olinda foi organizado no prédio do antigo colégio dos jesuítas, mostra a Universidade de Coimbra como importante centro de formação da elite letrada brasileira.

Azevedo trata a expulsão dos jesuítas por Pombal como danosa à vida escolar da Colônia:

Assim terminou, no período colonial, com a expulsão da Companhia, a obra dêsses missionários que, em mais de dois séculos, educaram a mocidade brasileira e tão eficazmente auxiliaram os portuguêses a colonizar o Brasil, amaciando a aspereza dos costumes de uma época de violências e de rapinas, sopitando as discórdias entre casas-grandes, coarctando os abusos dos governos, retemperando a fé, avivando a caridade, apertando os freios da religião e contrubuindo para implantar a ordem e a disciplina onde tudo conspirava para enraizar a anarquia, filha de ódios civis e das lutas de classes e de raças.(Azevedo, 1958, p. 46/47)

Ele continua a exaltação da obra missionária “sobrenatural” dos Jesuítas, em tom poético, que culmina com a alusão ao exílio de que são vítimas:

A obra civilizadora dêsses homens que surgiram do mar, nas caravelas, para se espalharem pelo litiral e, ao longe pelos sertões, toca, de fato, ao sobrenatural, para os civilizados anêmicos que nós somos, amigos de prazeres. 0 ardor apostólico, 0 desprêzo da morte, a mobilidade inverossímil em todos os terrenos e a sua capacidade de organização e disciplina não se podem medir, na sua grandeza, senão pela serenidade e resignação, com que abandonam os seus colégios e partem para o exílio, silenciosos soldados que dobram as suas tendas [...]. (Azevedo, 1958, p. 47)

Na bibliografia deste capítulo do livro de Azevedo, encontramos arroladas as obras de Serafim Leite a que ele recorreu, lista que queremos aqui destacar:

Leite (Pe Serafim), S.J. - Páginas de história do Brasil. II. As primeiras escolas do Brasil (Brasiliana), Págs. 35-62. Série Brasiliana, vol. 93. Com. Editora Nacional, São Paulo, 1937; História da Companhia de Jesus no Brasil (Século XVI). 2 volumes, Lisboa, 1938; Novas Cartas Jesuíticas (De Nóbrega a Vieira), Série Brasiliana, vol. 194, Comp. Editora Nacional, São Paulo, 1940. (Azevedo, 1958, p. 58) 
No entanto, o tom apologético à missão dos jesuítas, na obra de Serafim Leite e de seus leitores não terá sido obra do acaso.

Domingos Maurício, em notas biográficas à revista Brotéria, após a morte de Serafim Leite, datadas de janeiro de 1970, relata o momento em que foi dada ao jesuíta, então redator daquele periódico, por Cândido Mendes, superior provincial dos Jesuítas portugueses, a missão de confiança de escrever a obra que o tornaria famoso:

Neste momento histórico esboçavam-se, Além-Atlântico, arremeços de um surto nativista. Era preciso empreender, a tempo, em bases amplas e rigorasamente objectivas, a História da Companhia de Jesus no Brasil. Serafim Leite, antigo imigrante da Amazônia, afeito a vivências duras e contrastes naturais, era bem "the right man, in the place". [...] Serafim Leite aceitou com júbilo a incubência [...]. Quando em 1938 surgiram os dois primeiros volumes da História da Companhia de Jesus no Brasil, os aplausos estrugiram em Portugal, Além-Atlântico e pela Europa, nos mais diversos sectores de opinião [...]. Perante os olhos atônitos do leitor, ia desfilando a milícia apostólica de Nóbrega, cheia de audácia e zelo abnegado. (Maurício, 1970, p. 167-168)

Vale aqui aludir ao fato de que o historiador C.R. Boxer, no livro Salvador de Sá and the Struggle for Brazil and Angola - publicado em 1952, em Londres, e ainda, no ano de 1973, em versão portuguesa, pela Companhia Editora Nacional - também se servira fartamente da obra de Serafim Leite para caracterizar a ação educativa dos Jesuítas na colônia do Brasil, o que pode ser facilmente verificado por seus leitores.

Dessa forma, desde que começou a circular, em Portugal e no Brasil, a obra de Serafim Leite tornou-se referência obrigatória para os estudos sobre os jesuítas no processo de colonização do Brasil. Será ele inclusive o responsável pela edição das "cartas jesuíticas", de que também se serve Fernando de Azevedo, cujo significado pode ser apreendido na descrição abaixo:

Os intelectuais da Companhia de Jesus dedicam especial atenção ao registro de sua própria história e para tanto juntaram uma gigantesca coleção de documentos intitulada "Monumenta Historica Societatis Jesu", com mais de 80 volumes. 0 conjunto denominado "Monumenta Brasilica", editado pelo padre Serafim Leite, contém as cartas que nos interessam aqui e abrange os tomos 79 a 81 da série mais ampla. Ao lidar com esas fontes tem-se a impressão de estar diante de um enorme e solene monumento oficial digno de ser reverenciado com o maior rigor da metodologia historiográfica. 0 peso é tamanho que o grande público naturalmente evitaria tal literatura, como se não contivesse nada exceto notas de rodapé, mofo e latinismos. Tanta pompa acaba dificultando o acesso às cartas, enquanto simples relatos de uma experiência vivida. (Gambini,1988, p. 69) 
No que se refere à memória histórica dos jesuítas no Brasil, o estudo de Serafim Leite é o melhor exemplo de síntese e atualização, por ter sido uma missão atribuída pela Companhia ao referido jesuíta, ou seja, mostrar a dimensão cultural excepcional da obra missionária dos jesuítas no Brasil e ressaltar que a Companhia não deixou de existir após a perseguição de Pombal, da Monarquia Constitucional e da República portuguesa. Tratava-se de um dever, no sentido moral, conforme é destacado pelo filósofo maior das relações entre história e esquecimento e que levanta, para além disso, a questão dos riscos abusivos da memória, quando esta é alvo de manipulação.

A questão colocada pelo dever de memória excede assim os limites de uma simples fenomenologia da memória. Ela excede até os recursos de inteligibilidade de uma epistemologia do conhecimento histórico. Finalmente, enquanto imperativo de justiça, o dever de memória se inscreve numa problemática moral [...]. (Ricoeur, 2007, p. 104)

Seja como for, ao salientar o protagonismo dos jesuítas na formação social do Brasil colonial, a obra de Serafim Leite terá contribuido, obviamente, para o esquecimento da importância econômica e cultural dos contingentes humanos autóctones e daqueles que foram transladados da África. Reconhecemos assim uma afinidade ideológica entre a obra de Serafim Leite e a de Fernando de Azevedo, pela ênfase coincidente dada por ambos ao papel educativo dos jesuítas, no processo de colonização do Brasil, a qual, também está presente na crítica dirigida por eles à política pombalina que resultara na famosa expulsão. Sabemos ainda da proximidade temporal e social estabelecida entre os dois intelectuais, naquela ambiência política de um Brasil que buscava para si um rosto próprio de nação.

\section{Considerações Finais}

A abordagem da temática delineada neste artigo tem por base uma concepção de método, que entende a memória como dimensão fenomenológica, a história como questão epistemológica e o esquecimento como parte da trama dos sujeitos históricos e campo de enquadramento hermenêutico da educação no Brasil. Por meio dessa concepção, que citaremos logo adiante, temos um roteiro para entender como a memória é arquivada e passa para a representação historiadora através da explicação e/ou comprensão.

Os discursos escritos exercitam o uso da memória relativa aos feitos dos jesuítas como educadores e religiosos, apontam datas e lugares, sentidos das escolhas por políticos e intelectuais. Dirigidas por tais indicações, surgem as publicações de Serafim Leite e, atraídos por suas revelações, seus leitores, quando seus livros começam a circular entre as instituições e acervos, arquivos e bibliotecas. A sua 
missão maior é recuperar a justa memória da Companhia de Jesus, em combate ao esquecimento advindo da ação dos seus inimigos. Dela nasce o seu intuito de rememoração, no sentido posto abaixo:

Com a rememoração, enfatiza-se o retorno à consciência despertada de um acontecimento reconhecido como tendo ocorrido antes do momento em que esta declara tê-lo sentido, percebido, sabido. A marca temporal do antes constitui, assim, o traço distintivo da recordação, sob a dupla forma da evocação simples e do reconhecimento que conclui o processo de recordação. (Ricouer, 2007, p. 73)

Chama a nossa atenção que várias dessas publicações em livros sejam feitas em datas do calendário religioso da Companhia de Jesus, mas também civil, quando os jesuítas são homenageados pelo Estado nacional. A iniciativa se dá no contexto de um Brasil, que se faz moderno e anda em busca de um perfil identitário, e solicita a Serafim Leite a reedição de suas Cartas dos Jesuítas no Brasil, por ocasião do aniversário de 400 anos da cidade de São Paulo, quando Sérgio Buarque de Holanda dirige o Museu paulista.

Coincidência ou não, o sentido da educação colonial e a origem das instituições escolares do Brasil terão sido obra da Companhia de Jesus, tanto na visão de Serafim Leite, quanto na de Fernando de Azevedo, ainda que os dois intelectuais encarnem ideários e representem instituições distintas: a Igreja Católica e a República brasileira. Como diria Ricouer, trata-se este caso de um espaço habitado e de um tempo histórico povoado de testemunhos e arquivos, que promovem pouco a pouco uma dada mentalidade e posterior representação historiadora, a qual será constituída por narradores e recuperação de imagens, onde ressaltam a figura de um protagonismo irrecusável e de um ato justiceiro.

Trata-se de uma operação da memória em luta contra o esquecimento. Mais do que isso, de uma operação paradoxal de resistência, alimentada por um lado, por força de um republicanismo que, em Portugal, tentou extinguir a Companhia de Jesus e suas tradições e, no Brasil, nutre-se delas ou da força mítica da ação jesuítica colonial para supostamente erguer a nação civilizada.

A exemplo de Serafim Leite, Fernando de Azevedo tratará a expulsão dos jesuítas no interior da chamada Reforma Pombalina como um golpe cruel para o ensino, que teria gerado desorganização e pulverização de ações educativas e colocado em risco o sentido de unidade cultural da colônia brasileira. Vale a pena evocar a incisiva passagem em que o citado autor afirma:

A reforma pombalina planejada para o Reino, não só golpeou profundamente, na Colônia, o ensino básico geral, pulverizando-o nas aulas de disciplinas isoladas laulas régias), sem qualquer plano sistemático de estudos, como ainda cortou, na sua evolução pedagógica normal, o desenvolvimento do ensino para os planos superiores [...]. A unidade fundamental de pensamento que dava à Companhia e aos seus órgãos de ação o poder e a preponderância que teve na vida espiritual do povo brasileiro, como 
por toda a parte, transmitia-se, através de uma organização cerrada e admiravelmente hierarquizada, que facilitava o enquadramento de todos os seus reursos de ação, favorecendo a um tempo a unidade e a autonomia dos colégios [...]. (Azevedo, 1958, p. 53)

A defesa dos jesuítas é feita pelo autor, de forma clara e contudente. Ainda que seja ele um dos principais representantes do movimento escolanovista e da defesa do ensino laico no Brasil, conforme expressa fartamente a nossa historiografia educacional, a exemplo de Saviani (2007). Fernando de Azevedo toma partido, elogia, defende, critica inimigos e quer fazer justiça à grande obra de educadores dos missionários da Companhia de Jesus.

Trata-se de um paradigma muito similar ao da missão de Serafim Leite: mostrar a importância histórica da Companhia de Jesus no processo de colonização do Brasil e a injusta perseguição a ela dirigida pelo Estado de Pombal, pela Monarquia Constitucional e República portuguesa. Se ao fazer isso terão partilhado Serafim Leite e Fernando de Azevedo uma mesma missão e/ou consolidado uma narrativa cheia de exagero e supervalorização dos jesuítas, só o exercício da crítica histórica poderá melhor avaliar.

\section{Referências}

AZEVEDO, Ferdinand. A Missão Portuguesa da Companhia de Jesus no Nordeste Brasileiro. Recife, Fundação António dos Santos Abranches, 1986.

AZEVEDO, Fernando de. A Cultura Brasileira: introdução ao estudo da cultura no Brasil. São Paulo, Edições Melhoramentos, 1958.

AZEVEDO, Gonzaga de. Proscritos - 2 volumes $\left(1^{\circ}\right.$ editado em 1910 e $2^{\mathrm{a}}$ parte $/ 2^{\circ}$ volume. E. Daem/Bruxelas, 1914. (311 p.)

BOXER, Charles Ralph. Salvador de Sá e a luta pelo Brasil e Angola 1602-1686. São Paulo, Editora Nacional, Editora da Universidade de São Paulo, 1973.

Dicionário Histórico de la Compãnia de Jesús - Biográfico - Temático. Directores: Charles E. O'Neill, S.I. Joaquin Maria Dominguez, S.I. Roma, Institutum Historicum; S.I/Madrid, Universidad Pontifícia Comillas, (2001), pp. 2326- 2327)

FRANCO, José Eduardo. O Mito dos Jesuítas: em Portugal, no Brasil e no Oriente (Séculos XVI a XX). Lisboa, Gradiva, 2006, vol. I.

GAMBINI, Roberto. O Espelho Índio: os jesuítas e a destruição da alma indígena. Rio de Janeiro, Editora Espaço e Tempo, 1988.

MAURÍCIO, Domingos. Serafim Leite. In: Brotéria - cultura e informação. Lisboa, Livraria do Apostolado da Imprensa. Vol. 90, nº 1. Jan. 1970, p. 164-173.

PINHO, Inocêncio. O Historiador da Missionação Jesuítica no Brasil - Centenário de Serafim Liete, S.J., 1890- 1990. In: Brotéria - Cultura e Informação. Série mensal, vol. 131, n 1, julho de 1990. 
LEITE, Serafim. Breve História da Companhia de Jesus no Brasil (1549-1760). Braga/ Portugal, Livraria A.J. (Apostolado da Imprensa), 1993.

LEROY, Michel. O mito jesuíta. Lisboa, Roma Editora, 1999.

RICOUER, Paul. A memória, a história e o esquecimento. Campinas, Editora Unicamp, 2007.

SAVIANI, Dermeval. História das Idéias pedagógicas no Brasil. Campinas: Autores Associados, 2007.

Recebido em abril de 2013

Aprovado em julho de 2013

Maria Juraci Maia Cavalcante possui Doutorado em Ciências Econômicas e Sociais pela Universitat Oldenburg/Alemanha (1995), Pós-Doutorado em História Educacional na Universidade de Colônia/Alemanha (1999) e na Universidade de Lisboa (2006/2007). É professora Titular do Departamento de Estudos Especializados, da Faculdade de Educação da Universidade Federal do Ceará, na área de História Social e Política Educacional. Email: juraci.maialapq.cnpq.br 